\title{
Synthesis of Some Novel Complexes of La(III),Pr(III) Rare Earth Metals with 5-Acetamido-1,3,4-thiadiazol-2- sulphonamide and their Biological Activity
}

\author{
KAVITA L. KENDRE ${ }^{*}$, GIRISH PANDE ${ }^{1}$ and S. R. PINGALKAR ${ }^{2}$ \\ Department of Chemistry, ${ }^{1}$ Yeshwant College, Nanded -431601, India \\ ${ }^{2}$ Science College, Nanded, India \\ kavitalkendre@gmail.com
}

Received 3 May 2014 / Accepted 16 May 2014

\begin{abstract}
Complexes of $\mathrm{La}(\mathrm{III})$ and $\operatorname{Pr}(\mathrm{III})$ were synthesized by using tridentate ligand 5-acetamido1,3,4-thiadiazole-2-sulphonamide, having the general formula $\mathrm{ML}_{2}$. The complexes were characterized by IR, UV, elemental analysis, TGA, magnetic moment, conductivity etc. The conductivity data suggests their electrolytic nature. Spectral studies and magnetic susceptibility measurements revealed an octahedral geometry for all the complexes. The ligand and it's complexes were screened for their antimicrobial activity against E. coli, S. aureus, A. niger, Alternaria.
\end{abstract}

Keywords: Acetazolamide, Electrolytic, Antimicrobial activity

\section{Introduction}

Interest in the co-ordination behaviour of acetazolamide (5-acetamido-1,3,4-thidiazole-2sulfonamide) arises from several reasons AZM is a diuretic sulfonamide used clinically, whose therapeutic action can be explained from the potent inhibition of the $\mathrm{Zn}$ (III) metalloenzyme carbonic anhydrase. There is much evidence reported in the literature, including crystal structures and spectral data, that shows the inhibitor reacting with the enzyme by direct coordination with the metal ${ }^{1,2}$. Although the sulfonamide deprotonated moiety is generally considered the portion of the AZM that interacts with the $\mathrm{Zn}(\mathrm{II})$, there is no solid experimental basis to state this concept ${ }^{3}$. So it seems to be interesting to investigate which are the best coordination positions of the AZM molecule, which has two ionazable proton and several donar atoms on the other hand, since this ligand presents a diazole group, the complexes of AZM and essential trace ions could represent one of the simplest models for the natural metalloenzymes.

Aromatic sulfonamides and their derivative compounds with 1,3,4-thiadiazole constitute an important group of carbonic anhydrase inhibitors. The inhibition of this enzyme by sulfonamide drugs finds clinical application in the treatment of glaucoma, epilepsy and other disorders. On the other hand, these compounds have also played an important role in the physicochemical and enzymatic studies on carbonic anhydrase ${ }^{4}$. 
The systemic carbonic anhydrase inhibitor (CAI), acetazolamide \{5-acetamido-1,3,4thiadiazole-2-sulfonamide (ACZ) (Scheme 1), is generally used for the treatment of glaucoma $^{5-6}$ and epilepsy ${ }^{7-8}$ and also as diuretic ${ }^{9}$.<smiles>CC(=O)Nc1nnc(S(N)(=O)=O)s1</smiles>

Metal ions play an important role in altering biochemical properties of the sulfonamide based drugs, and indicate a new direction in the impact of chemotherapeutic agents and lowering toxicity. The studies have proved that the metal complexes of sulfonamides possess much stronger CAI properties than the sulfonamides themselves from which they were prepared ${ }^{10-12}$. Some metal complexes of 1,3,4-thiadiazole derivatives have been reported as in vitro inhibitors of the zinc enzyme carbonic anhydrase ${ }^{13}$, whereas in vivo studies showed good antiepileptic action for some $\mathrm{Cu}(\mathrm{II})$ and $\mathrm{Zn}(\mathrm{II})$ complexes of the sulfonamide type ligands ${ }^{14}$. Finally, some 2,5-disubstituted -1,3,4-thiadiazoles as well as their $\mathrm{Cu}(\mathrm{II})$ complexes were reported to act as fungitoxic agents ${ }^{15}$.

These properties obviously originate from the binding mode of metal ions that may cause a significant influence on the redox properties of these drugs. Therefore, the studies on acetazolamide as a sulfonamide derivative and its metal complexes have been reported in the literature ${ }^{16,17}$.

The apparent formula of acetazolamide is given in Scheme 1. As can be seen from Scheme 1 that its metal-complexation can be formed by means of acetamide and/or sulfonamide $\mathrm{NH}$ groups as monoanion and dianion for the metal ions which can be crucially important in biological processes ${ }^{18,19}$. Although the spectroscopic and thermal characterization studies of metal(II) acetazolamide complex have been carried out to illuminate the interaction processes ${ }^{20,21}$.

The introduction of nitrogen atoms into the structure of organic compounds often resulted in important changes in their behaviour towards metal ions. Many investigations were undertaken of the interaction of metal ions with ligands containing oxygen and nitrogen as donor atoms ${ }^{22,23}$. In the present study, metal complexes of La(III) and Pr (III) with 5-acetamido-1,3,4-thiadiazole-2-sulphonamide (acetazolamide) were synthesized and characterized in view of their importance in biological systems ${ }^{24,25}$.

\section{Experimental}

All the chemicals used were of analytical grade. Pure ethanol and distilled water were used for preparation of the solutions. Acetazolamide was obtained from sigma chemical company (U.S.A) Metal chlorides were obtained from Alfa Acer company.

\section{Preparation of complex}

For the synthesis of complex, ligand metal ratio was confirmed by conductometric titrations using monovariation method on Systronics conductivitymeter using dip type electrode. Conductometric titrations supported $2: 1$ (L:M) ratio in the complex was further supported by Job's method ${ }^{26}$ of continuous variation as modified by turner and Anderson ${ }^{27}$. The stability constant and free energy change values were also calculated.

A solution of metal chloride in absolute ethanol was added drop wise to a solution of ligand acetazolamide in absolute ethanol and refluxed for $4-5 \mathrm{~h}$. After the mixture had been maintained at pH 7-8 by adding liquor ammonia. The precipitate was filtered off, washed with ethanol and dried in vacuo. The compound was obtained as yellow powder. 


\section{Analytical procedure}

Acetazolamide and rare earth metal chlorides were used as received from S.D. fine chemicals. The solvents were a solution of distilled before use a distilled water was used for the preparation and analyses. The molar conductivity at room temperature was determined in conductivity water using a dip type cell with a smooth platinum electrode. The magnetic susceptibility measurements were made by Gouy's method at room temperature using powdered samples of complexes.

The electronic absorption spectra of the complexes in DMSO were recorded on a Shimadzu double beam UV-Visible spectrophotometer model UV 150-02. The infrared spectra of the solid samples in the $500-4000 \mathrm{~cm}^{-1}$ were recorded on a Shimdzu FTIR spectrophotometer and Brueker FTIR spectrophotometer using $\mathrm{KBr}$ pellets. The thermal analyses (TGA) for the complexes were recorded on a perking Elmer STA 6000 under nitrogen atmosphere at room temp to $1000{ }^{\circ} \mathrm{C} 5 \mathrm{mg}$ of the samples with the heating rate of $10{ }^{\circ} \mathrm{C}$ per min and the platinum cups as sample holders.

\section{Result and Discussion}

These complexes are air stable, colored, solid which decompose above $>300{ }^{0} \mathrm{C}$. The molar conductance value of complexes indicating their electrolytic nature. The values of magnetic moment of complexes are indicating diamagnetic and paramagnetic nature. $\mathrm{La}$ (III) complex had not ligand filed stabilization effecting to complete f-sub shell, therefore $\mathrm{La}$ (III) complex should be diamagnetic spin free octahedral complex with $\mathrm{d}^{10}$ system. The elemental analyses indicate that the complexes of AZM with La(III) and Pr(III) can be formulated as ML2 (Table 1-3).

Table 1. Physical characteristics of complexes

\begin{tabular}{cccc}
\hline Comp & M : L ratio & Color & Yield, \% \\
\hline AZM & - & White & 60 \\
{$\left[(\mathrm{AZM})_{2} \mathrm{La}\right]_{3} \mathrm{Cl} .2 \mathrm{H}_{2} \mathrm{O}$} & $1: 2$ & Off white & 55 \\
{$\left[(\mathrm{AZM})_{2} \mathrm{Pr}\right]_{3} \mathrm{Cl} \cdot 2 \mathrm{H}_{2} \mathrm{O}$} & $1: 2$ & Light Pista & 55 \\
\hline
\end{tabular}

Table 2. Analytical data of complexes

\begin{tabular}{|c|c|c|c|c|c|c|c|c|}
\hline \multirow{2}{*}{ Complex } & \multicolumn{7}{|c|}{ Elemental Analysis \% found (calculated) } & \multirow{2}{*}{${ }^{\mathrm{M} . P .} \mathrm{C}$} \\
\hline & $\mathrm{C}$ & $\mathrm{H}$ & $\mathrm{N}$ & $\mathrm{S}$ & $\mathrm{O}$ & $\mathrm{Cl}$ & $\mathrm{M}$ & \\
\hline $\mathrm{C}_{8} \mathrm{H}_{16} \mathrm{LaCl}_{3} \mathrm{~N}_{8} \mathrm{O}_{8} \mathrm{~S}_{4}$ & $\begin{array}{c}12.90 \\
(12.36)\end{array}$ & $\begin{array}{c}2.15 \\
(3.01)\end{array}$ & $\begin{array}{c}15.05 \\
(14.85)\end{array}$ & $\begin{array}{c}17.20 \\
(17.99)\end{array}$ & $\begin{array}{c}17.20 \\
(20.12)\end{array}$ & $\begin{array}{c}14.29 \\
(13.65)\end{array}$ & $\begin{array}{c}18.68 \\
(17.86)\end{array}$ & $>300$ \\
\hline $\mathrm{C}_{8} \mathrm{H}_{16} \mathrm{PRCl}_{3} \mathrm{~N}_{8} \mathrm{O}_{8} \mathrm{~S}_{4}$ & $\begin{array}{c}12.87 \\
(12.50)\end{array}$ & $\begin{array}{c}2.14 \\
(205)\end{array}$ & $\begin{array}{c}15.01 \\
(15.56)\end{array}$ & $\begin{array}{c}17.16 \\
(17.56)\end{array}$ & $\begin{array}{c}17.16 \\
(17.34)\end{array}$ & $\begin{array}{c}14.26 \\
(14.09)\end{array}$ & $\begin{array}{c}18.89 \\
(18.34)\end{array}$ & $>300$ \\
\hline
\end{tabular}

Table 3. Analytical data of complexes

\begin{tabular}{cccc}
\hline Complex & $\begin{array}{c}\text { Magnetic moment } \\
\mu_{\text {eff }} \text { BM }\end{array}$ & $\begin{array}{c}\text { Molar conductance } \\
\text { ohm }^{-1}\end{array}$ & Mol. Wt. \\
\hline$\left[(\mathrm{AZM})_{2} \mathrm{La}\right] 2 \mathrm{H}_{2} \mathrm{O} .3 \mathrm{Cl}$. & Diamagnetic (-) & Electrolytic (102) & 743.80 \\
{$\left[(\mathrm{AZM})_{2} \mathrm{Pr}\right] 2 \mathrm{H}_{2} \mathrm{O} .3 \mathrm{Cl}$.} & Paramagnetic (3.40) & Electrolytic (111) & 745.75 \\
\hline
\end{tabular}

Infrared spectral study

The IR spectra of Acetazolamide shows (Table 4) two sharp peaks at $3294 \mathrm{~cm}^{-1}$ and as 3178 $\mathrm{cm}^{-1}$ for primary amine group $\left(-\mathrm{NH}_{2}\right)$ which were shifted to lower frequency at 3197 and 3115 in La(III)-AZM complex and at 3180 and 3093 in Pr(III)-AZM complex, it indicates coordination of $\mathrm{N}$ to metal ion. The $\mathrm{C}=\mathrm{N}$ (azomethine) group in acetazolamide shows sharp 
peak at $1651^{28-30} \mathrm{~cm}^{-1}$ which shifted to lower frequencies in the metal complexes to i.e. $1645 \mathrm{~cm}^{-1}$ and $1600^{31} \mathrm{~cm}^{-1}$. It indicates $\mathrm{N}$ in $\mathrm{C}=\mathrm{N}$ group shows coordination with metal ion. The value of $-\mathrm{NH}$ group in ligand is $3091 \mathrm{~cm}^{-1}$ which shifted to lower frequency in complexes to $3024 \mathrm{~cm}^{-1}$ and $3026 \mathrm{~cm}^{-1}$ showing of co-ordination of $\mathrm{N}$ in $-\mathrm{NH}$ group with metal. A broad peaks of water molecule are present in complexes ${ }^{32}$ at $3300 \mathrm{~cm}^{-1}$ and $3305 \mathrm{~cm}^{-1}$. The new IR bands appearing at $557 \mathrm{~cm}^{-1}$ and at $560 \mathrm{~cm}^{-1}$ are assigned toM $-\mathrm{N}^{33}$ in $\mathrm{La}$ (III) and $\operatorname{Pr}(\mathrm{III})$ complexes respectively.

Table 4. IR bands of La (III), Pr(III) complexes, AZM ligand

\begin{tabular}{cccc}
\hline Ligand & La(III) complex & Pr(III) complex & Assignment \\
\hline 3294,3178 & 3197,3115 & 3180,3093 & $-\mathrm{NH}_{2}$ \\
1651 & 1645 & 1600 & $\mathrm{CH}=\mathrm{N}$ \\
3091 & 3024 & 3026 & $-\mathrm{NH}$ \\
- & 557 & 560 & $\mathrm{M}-\mathrm{N}$ \\
1680 & 1678 & 1678 & $\mathrm{C}=\mathrm{O}$ \\
- & 3305 & 3300 & $\mathrm{H}_{2} \mathrm{O}$ \\
\hline
\end{tabular}

\section{Electronic spectral data}

The ultraviolet region band shift and intensity alternation ${ }^{34}$ of ligand indicates involvement of ligand in the chelation with lanthanide ions. The ligand acetazolamide shows strong band at $316 \mathrm{~nm}$ (Table 5 \& Figure 1). In case of La(III) complexes the strong bond observed at 266 $\mathrm{nm}$ and $\operatorname{Pr}(\mathrm{III})$ complex the strong bond observed at $284 \mathrm{~nm}$. These shifting in the value of bond alternation indicates the involvement of ligand in chelate formation.

Table 5. Electronic Spectral Data

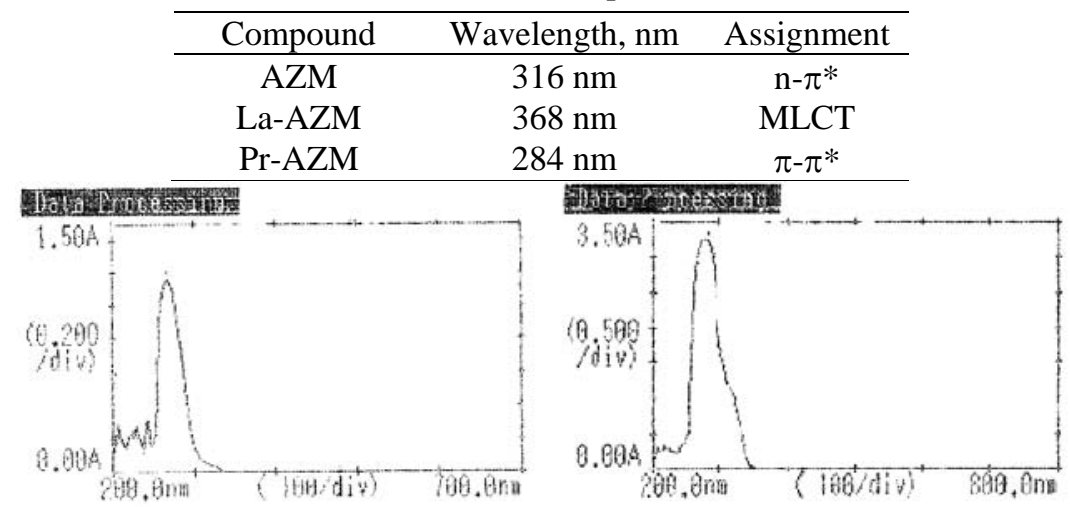

Figure 1. Electronic Spectra of La-AZM complex Electronic Spectra of Pr-AZM complex

\section{Thermal analysis}

In La(III) AZM complex, in first step two lattice water molecules (8.60\%) lost at RT-200 ${ }^{0} \mathrm{C}$ temperature. The 2-CO- $\mathrm{CH}_{3}$ and $2 \mathrm{NH}_{2}-\mathrm{SO}_{2}$ of ligand (33.07\%) lost in second step at 200$260{ }^{0} \mathrm{C}$. In third step organic moiety and $3 \mathrm{Cl}^{-}(40.92 \%)$ are lost at $260-765{ }^{\circ} \mathrm{C}$. Finally residue $\left(21.91 \%\right.$ ) remain at $765-1000{ }^{\circ} \mathrm{C}$ (Table 6 \& Figure 2).

In Pr(III)-AZM complex two lattice water molecules (7.23\%) lost at RT-140 ${ }^{0} \mathrm{C}$. The 2$\mathrm{CO}-\mathrm{CH}_{3}$ and $3 \mathrm{Cl}^{-}$part $(25.05 \%)$ at $140-250{ }^{\circ} \mathrm{C}$. In third step remaining organic moiety $(47.15 \%)$ at $250-775{ }^{\circ} \mathrm{C}$. Finally residue $(21.50 \%)$ at $775-1000{ }^{\circ} \mathrm{C}$. 


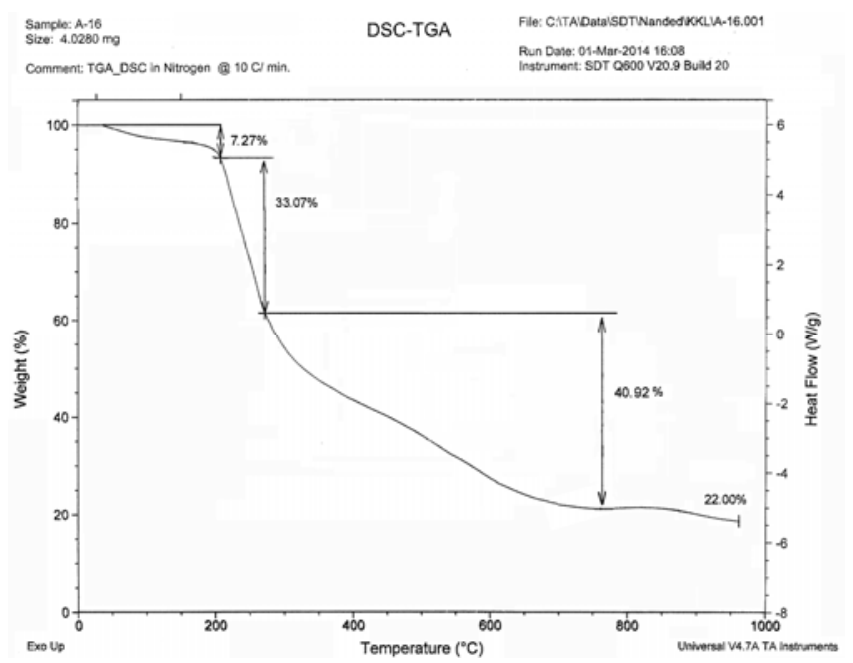

Figure 2. TGA of La-AZM complex

Table 6. TGA Analysis of La (III) AZM complex

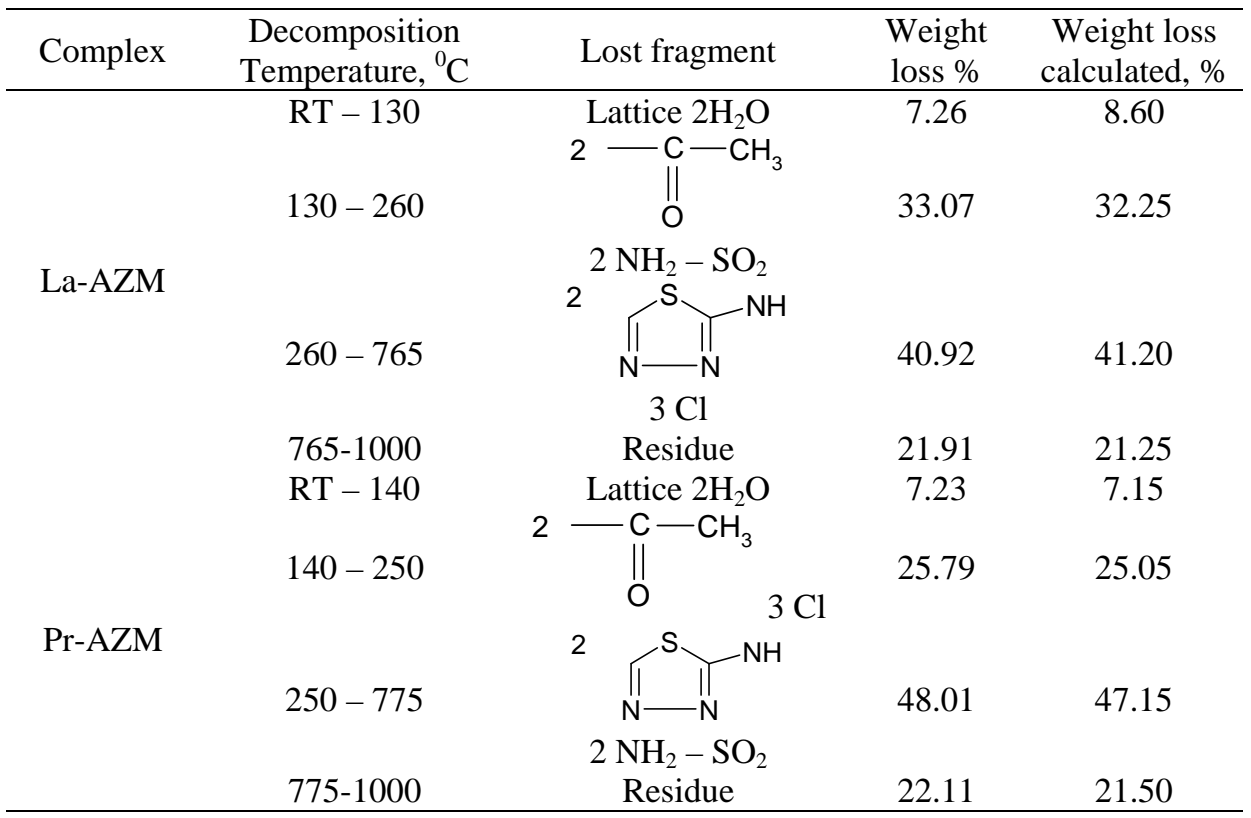

\section{Co-ordination geometry}

Due to large size, lanthanide ions generally have co-ordination number higher than that of transitions metal ions. Based on the analytical, spectral, thermal data the six co-ordination around the $\mathrm{La}(\mathrm{III})$ and $\operatorname{Pr}(\mathrm{III})$ ions is proposed. The 3 chloride anion and two water molecules are expected to be outside the co-ordination sphere. The lanthanum and praseodymium ion expected to posses six co-ordinated geometry with tridentate two acetazolamide molecule. 


\section{Antioxidant properties}

The results of antioxidant testing of the new acetazolamide complex is summarized in Table 8 . The comparison of the results with control, acetazolamide and $\mathrm{La}(\mathrm{III})$-acetazolamide and P(III)racetazolamide complex is done. The complexes are more antioxidative than control and ligand.

Table 8. \%Inhibition efficiency data

\begin{tabular}{ccccc}
\hline Compound & Initial wt & Final wt & Different & \% I.E. \\
\hline Control & 0.443 & 0.431 & 0.012 & - \\
Acetazolamide & 0.395 & 0.384 & 0.009 & 25 \\
La-AZM complex & 0.424 & 0.417 & 0.007 & 41 \\
Pr-AZM complex & 0.428 & 0.412 & 0.006 & 50 \\
\hline
\end{tabular}

\section{Antimicrobial activity}

Above synthesized compound and the ligand have been screened against bacteria E.coli and staphalococcus aureus and fungi aspergillus Niger and alternaria. Nutrient agar as medium used for bacteria and potato dextrose Agar used for fungi. Incubation of plates with complex solution and ligand solution in well done for $48 \mathrm{~h}$ at $27{ }^{\circ} \mathrm{C}$ temperature.

The zone of inhibition based upon size around the well was measured. Inhibition zone percentage are recorded in Table 3. The percentage inhibition of growth by ligand is less than acetazolamide metal complex. Thus complex shows greater activity against microorganisms as compared to ligand acetazolamide. This prove that the chelation increases the antimicrobial activity. Results are presented in Table 9.

Table 9. Antimicrobial activity of ligand and Ce(III) complex

\begin{tabular}{ccccc}
\hline Ligand / & \multicolumn{4}{c}{ \% of Inhibition Zone } \\
\cline { 2 - 5 } Complex & E.Coli & S.Aureus & A.Niger & Alternaria \\
\hline Ligand & 11 & - & - & 04 \\
La(III) AZM & - & 09 & - & - \\
Pr(III) AZM & - & 06 & - & 11 \\
\hline
\end{tabular}

\section{Conclusion}

Hence on the basis of elemental analysis, IR spectra, UV, spectra, magnetic moment data, conductivity measuremen and TGA data, following octahedral structure are proposed for La(III)-AZM complex and Pr(III)-AZM complex as follows,

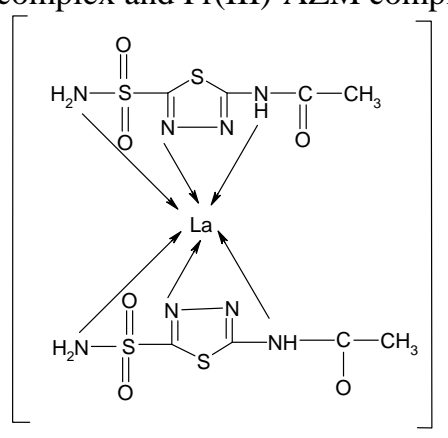

$2 \mathrm{H}_{2} \mathrm{O} \cdot 3 \mathrm{Cl}$

$$
\mathrm{M}=\mathrm{La}(\mathrm{III}) \text { AND Pr(III) }
$$

The results of antioxidative activity conclude the synthesized La(III)-AZM and Pr(III)AZM complexes has better antioxidative activity than acetazolamide. The results of antimicrobial activity conclude the synthesized La(III)-AZM and Pr(III)-AZM complex of AZM has better antimicrobial activity than acetazolamide. 


\section{References}

1. Kanan K K, Ramanadham M and Jones T A, Ann N YAcad Sci., 1984, 429, 49-60.

2. Lindakog S, Carbonic Anhydrase, in Advances in inorganic Biochemistry Eichorn G L, Marzilli L, Eds., Ehevier North Holland, New York, 1981, 4.

3. Vadani A, Doble M and Dunitz J D, J Comput Chem., 1986, 7(6), 701-710; DOI:10.1002/jcc.540070602

4. Chuf'an E E, Suvire F D, Enriz R D and Pedregosa J C, Talanta, 1999, 49(4), 859-868; DOI:10.1016/S0039-9140(99)00093-4

5. Kaur I P, Smitha R, Aggarwal D and Kapil M, Int J Pharm.. 2002, 248(1-2), 1-14; DOI:10.1016/S0378-5173(02)00438-6

6. $\quad$ Sabri K and Levin A V, J AAPOS., 2006, 10(5), 464-468.

7. Lim L L, Foldvary N, Mascha E and Lee J, Epilepsia, 2001, 42(6), 746-749; DOI:10.1046/j.1528-1157.2001.33600.x

8. Varadkar S, Duncan J S and Cross J H, Epilepsia, 2003, 44, 986-987; DOI:10.1046/j.1528-1157.2003.53002.x

9. $\quad$ Sterrett S P, Penniston K L, Wolf J S and Nakada S Y, Urology, 2008, 72(2), 278-281; DOI:10.1016/j.urology.2008.04.003

10. Supuran C T, Roum Chem Quart Rev., 1993, 1, 77-116.

11. Supuran C T and Scozzafava A, J Enzyme Inhib., 1997, 12(1), 37-51.

12. Mincione G, Scozzafava A, Supuran C T, Met Based Drugs, 1997, 4(1), 27-34; DOI:10.1155/MBD.1997.27

13. Brezeanu M, Olar R, Manole G and Supuran C T, Rev Roum Chim., 1992, 37, 425-431.

14. Alzuet G, Casanova G, Ramirez J A, Borr'as J and Carugo O, J Inorg Biochem., 1995, 57(3), 219-234; DOI:10.1016/0162-0134(94)00028-9

15. Thimmaiah K N, Chandrappa G T, Lloyd W D and Parkanyi C, Inorg Chim Acta, 1985, 107(1), 1-14; DOI:10.1016/S0020-1693(00)80680-5

16. Ferrer S, Jim'enez A and Borr'as J, Inorg Chim Acta, 1987, 129(1), 103-106; DOI:10.1016/S0020-1693(00)85910-1

17. Ferrer S, Hasnoot J G, de Graaf R A G, Reedijk J and Borr'as J, Inorg Chim Acta, 1992, 192(1), 129-138; DOI:10.1016/S0020-1693(00)83182-5

18. Ferrer S, Borr'as J, Miratvilles C and Fuertes A, Inorg Chem., 1990, 29(2), 206-210; DOI:10.1021/ic00327a012

19. Ferrer S, Borr'as J, Miratvilles C and Fuertes A, Inorg Chem., 1989, 28(1), 160-163; DOI:10.1021/ic00300a036

20. Ferrer S, Alzuet G and Borr'as J, J Inorg Biochem., 1989, 37(2), 163-174; DOI:10.1016/0162-0134(89)80039-X

21. Ferrer S, Borr'as J, Martin-Gil J and Martin-Gil F J, Thermochim Acta, 1989, 153, 205-220; DOI:10.1016/0040-6031(89)85434-6

22. Lindoy L G and Livingstone S E, Inorg Chim Acta, 1967, 1, 365-370; DOI:10.1016/S0020-1693(00)93203-1

23. Dwivedi R and Dhakarey R, J Indian Counc Chem., 2003, 20, 12.

24. Bhattacharya M, Iqbal S A and Malik S, Orient J Chem., 2004, 20, 643-646.

25. Malik S, Ghosh S and Jain B, Arch Appl Sci Res., 2010, 2, 304-306.

26. Job P, Ann Chim., 1936, 11, 97.

27. Turner S E and Anderson R C, J Am Chem Soc., 1949, 71(3), 912-914.

28. Rao C N R, Chemical Application of IR Spectroscopy, Academic Press, New York, 1963.

29. Nakamoto K, IR spectra of Inorganic and Coordination Compounds, Wiley, New York, 1956. 
30. Bilge S, Kilic Z, Zeliha H, Horkelek T and Safran S, J Chem Sci., 2009, 121(6), 989-1001; DOI:10.1007/s12039-009-0128-2

31. Mishra A P and Kumar K, J Indian Chem Soc., 2009, 86(11), 1150.

32. Arunachalam T, Bhakyaraj R and Sasi A K, J Chem., 2009, 6(3), 743-746; DOI:10.1155/2009/780192

33. Jose C V and Joy Anto T, Int J Chem Sci., 2008, 6(4), 1913-1919.

34. Seetharama Rao T and Laxma Reddy K and Lingaih, Ind Acad Sci (Chem. Science), 1988, 100(5), 333-373. 